\title{
HIV/AIDS Healthcare Information Delivery in Tanzania using Integrated Mobile Application and Web-based System: System's Functional and Non-functional Requirements
}

\author{
Ibrahim A. Mwammenywa \\ Nelson Mandela - African Institution of Science and Technology, P. O. Box 447, Arusha, Tanzania. \\ The University of Dar es Salaam, P. O. Box 35131, Dar es Salaam, Tanzania \\ E-mail: mwammenywai@nm-aist.ac.tz; a.m.ibra90@gmail.com \\ Shubi F. Kaijage \\ Nelson Mandela - African Institution of Science and Technology, P. O. Box 447, Arusha, Tanzania. \\ E-mail: shubi.kaijage@nm-aist.ac.tz
}

Received: 01 May 2018; Accepted: 12 August 2018; Published: 08 November 2018

\begin{abstract}
This study examines the functional requirements (FR) and non-functional requirements (NFR) for development of an integrated mobile application and a web-based system for enhancement of HIV/AIDS healthcare information delivery in Tanzania. The study was conducted in Dar es Salaam city in Tanzania. The unstructured interview was carried-out involving 45 people, among them, there were selected relevant users of the proposed system, Information Technologists, System Administrators and HIV/AIDS healthcare practitioners from the HIV/AIDS Care and Treatment Centers (CTCs) in district referral hospitals in Dar es Salaam. The captured requirements were classified into functional and non-functional requirements, the functional requirements were then graphically analyzed using the use case diagram, which was done by using starUML computer software. These findings can be used as the foundation's building block for the development of a mobile application and web-based system for HIV/AIDS healthcare information delivery services.
\end{abstract}

Index Terms-Mobile Health (m-health), HIV/AIDS Healthcare Information, Online HIV/AIDS Healthcare Information, Functional Requirements, Non-functional Requirements.

\section{INTRODUCTION}

The ever-increasing developments in the field of Information and Communication Technologies (ICT) such as mobile technologies have transformed how people access, share and use information in our societies [1]. The mobile technology is the technology of using cellular communication system for transferring of a specific information to the intended recipient(s). There has been a widespread usage of mobile technology as a vital medium for accessing and dissemination of information in various sectors such health, finance, and security and control systems. Mobile Technology has become the powerful communication and behavioral change tool due to its extensive availability and coverage; and inexpensiveness of mobile gadgets [2]. The everincreasing development in the field of ICT have transformed how people access, share and use information in our societies [1]. The evolution of mobile technologies and mobile devices has been among the contributing factors in the transformation of how information is accessed, shared and used. The advancement of mobile devices such as mobile phones and tablets has been a global phenomenon with mobile phone ownership surpassing computer ownership in many countries [3]. The widespread of mobile phones especially the smart-phones, has significantly led to an increase in advanced mobile applications for providing access to various information that are needed by the community [4].

In Tanzania, there is a diverse usage of mobile technologies such as mobile health (m-health), mobile money transactions (example M-Pesa), and mobile banking. Compared to the other media in the health sector, the mobile technology has been the fastest growing media recently [5-7]. The use of the mobile technology in health sector has directly targeted the general public. There is a mounting evidence that reveals the potential of mobile communications to fundamentally improve healthcare services especially in remote as well as in resource-scarce areas [8]. This has been conducted through engaging all health stakeholders, and consequently improving the time and quality access to the health-related services and information as well as inspiring the change of behavior to strengthen disease prevention [2, 9].

There is a need of extending the use of the mobile 
technologies in fighting against the Human Immunodeficiency Virus infection and Acquired Immunodeficiency Syndrome (HIV/AIDS) in Tanzania. [10] recommended that the HIV/AIDS public care providers, and the HIV/AIDS Care and Treatment Centers (CTCs) to use the electronic media to provide access to relevant and formal HIV/AIDS healthcare information. Particularly, healthcare information delivery for HIV care and treatment should make use of internet and mobile phones to reach many people for broader coverage and impact. This implies the usage of mobile and web-based application for enhancing the dissemination and delivery of HIV/AIDS healthcare information is the way forward.

When developing the mobile and/or web-based application for the delivery of HIV/AIDS healthcare information, the first stage in the system development is to well analyze, generate and document the desired specifications or requirements. System requirements are description or statements of a function, features or conditions that a user seeks to have implemented in a system and so the developer has to implement into his/her system [11]. The requirements specification process highly rests on the information flow to allow the communication between all sets of users and system developer so as to implement the right system [12]. The system requirements specification serves as the foundation for designing, implementation, testing and maintenance of the developed system [13]. In system development, the requirements are generally categorized into functional and non-functional requirements [11].

The functional requirements (FR) are requirements and/or services that a system should provide to the users and how the system should react to particular inputs from the users. Non-functional requirements (NFR) of the system are certain attributes which are the desired characteristics of the system $[14,15]$. NFR is what systems users call the generic quality attributes of the system [13].

This paper assesses the functional requirements and non-functional requirements for development of the mobile application and web-based system for delivery of the HIV/AIDS healthcare information. Moreover, this study maps the specific requirements into the use case diagram and going further to suggest the conceptual framework for the mobile application and web-based system for HIV/AIDS healthcare information delivery.

The rest of this paper is arranged as follows: the second section describes the background information on the current situation of HIV/AIDS pandemic, healthcare information delivery and the fear of stigma as a major problem. The third section talks about related works of which the mobile technologies have been applied to facilitate the delivery of HIV/AIDS healthcare information. The detailed research study design and methods used from the data collection, data analysis to results presentation have been explained in section four. Sections five provides the detailed explanation of the findings and discussion. Finally, the conclusion has been drawn in section six.

\section{BACKGROUND}

HIV/AIDS has been one of the most killing global pandemics to date, with approximately of 36.7 million people were living with HIV worldwide by 2015. Tanzania in particular, there were about 1.4 million people living with HIV (PLHIV), and around 36,000 deaths which occurred in 2015 were due to HIV/AIDS [16]. Tanzania currently has an HIV prevalence rate of 4.7 percent with statistics showing strong regional variation in Tanzania with Mbeya at 14 percent, Iringa at 13 percent and Dar Es Salaam at 11 percent leading in HIV prevalence $[17,18]$.

Currently, all of the HIV/AIDS healthcare service including the healthcare information delivery are offered at the CTCs across the country. However, fear of stigma is still holding some people in the society from freely going to the Care and Treatment Centers (CTCs) to receive the HIV/AIDS related health services such as counselling, treatment and HIV/AIDS related information which can inspire the change of behavior to strengthen HIV/AIDS prevention [19-21]. The People Living with HIV Stigma Index indicates that roughly one in every eight-people living with HIV is being denied health services because of stigma and discrimination [17]. [19] described that among different factors for fear of stigma among PLHIV, 37.4\% fear for unethical treatment of PLHIV and $31.1 \%$ for unofficial disclosure of their health status. This fear is due to the lack of a secured platform for accessing the HIV/AIDS healthcare information services. [10] recommended that the HIV/AIDS public healthcare providers, and the HIV/AIDS CTCs to use the electronic platform to provide a confidential access to relevant and formal HIV/AIDS healthcare information. Despite the need for the m-health platform for enhancement of HIV/AIDS healthcare delivery, there is no any m-health platform for dissemination of HIV/AIDS healthcare information in Tanzania to date. The electronic systems' developers seem to not have the system's requirements as the foundation to build the m-health system for HIV/AIDS healthcare information delivery.

This research study assesses the important requirements; both functional and non-functional requirements for developing a mobile application and web-based system platform for delivery of HIV/AIDS healthcare information. System requirement engineering is a critical stage of software development cycles that defines the services that the system is to provide and its operational constraints [22].

\section{RELATED WORKS}

In this section, the review of the similar platform for delivery of HIV/AIDS healthcare information is conducted. Furthermore, this paper also reviews a similar study on the system requirements for development of health information delivery system. 


\section{A. Similar Platform for HIV/AIDS Healthcare Information Delivery}

In 2001, the National AIDS Helpline was launched and is being operated by Tanzania Youth Alliance (TAYOA) using a Treatment toll free Hotline (also known as 117 Afya Treatment) [23-24]. The system delivers the HIV/AIDS healthcare information through phone calls. However, '117 Afya Treatment' system has encountered some challenges such as maintaining the user' confidential identity (or anonymity), since the use of the person mobile phone number risks to reveal his/her identity. Moreover, the system does not establish the client's medical profile with his/her clinical consultation history for future references by both HIV/AIDS practitioner and client himself/herself.

Since the platform risks to reveal the client's identity through his/her registered phone number and considering how the HIV/AIDS is the complicated disease with a lot of people fear of being identified and then being stigmatized [19-21] while using such platform. Therefore, this paper stipulates the functional and non-functional system requirements for development of the secure online platform for delivery of HIV/AIDS healthcare information.

\section{B. Similar Study on the Requirements for Health Information Delivery System}

[25] provides the similar study by examining the system requirements for the delivery of nutrition information to both prenatal and postnatal mothers. These requirements are used for delivering nutrition tips and nutrition specific recommendations to the system's clients. [26] used those requirements in implementation of the NutriMobile system for delivery of nutrition information to both prenatal and postnatal mothers.

Moreover, there some other online platforms for healthcare services such as Mobile Alliance for Maternal Action (MAMA) and Healthy Pregnancy, Healthy Baby (HPHB) [27, 28]. However, there is no any online platform for delivery of HIV/AIDS healthcare information in Tanzania up to the present moment. [6, 29] show the need for online delivery of HIV/AIDS healthcare information as their studies show that majority of people tend to try to access the internet-based HIV information, HIV/AIDS clinical tips and recommendations.

\section{METHODOLOGY}

The gathering of requirements was conducted in the Dar es Salaam city in Tanzania. For gathering and collection of system requirements for the development of a mobile application, this region was suitable since it indicates the highest usage of internet and mobile services and platforms in the country (Ministry of Communications and Transport [30, 31]. Moreover, statistically, Dar es Salaam is the region which statistically indicated a high HIV prevalence of about $11 \%$ percent [18], as well as high levels of stigma per
PLHIV about $49.7 \%$ percent as compared to $39.4 \%$ percent from other regions [32].

This research employed a mixed research methodology during the collection of different relevant data for establishment of the functional and non-functional requirements. Before data collection, the stakeholder analysis was conducted. This analysis was carried-out in order to gather substantive knowledge on the relevant actors so as to capture their specific requirements need on the proposed online platform for delivery of HIV/AIDS healthcare information. Identification of the stakeholders was key in the data collection for establishment of the functional and non-functional requirements for the proposed online platform.

During the stakeholder analysis, this study adopted the modified framework of [33]. This framework maps the typical rationale for stakeholder analysis, topology and respective methods. In analyzing the stakeholders, the main emphasis was on identifying them and then identify their roles in the HIV/AIDS healthcare information flow. The stakeholder identification was carried through analyzing the official procedures by the authority, TACAIDS in handling the HIV/AIDS healthcare clinical information flow [34-36].

After the identification of all key actors, the system requirements were collected qualitatively. Qualitative data collection method was utilized, which consists of investigation for particular information using unstructured interview, casual talks and in-depth discussion [37]. This was conducted in the district referral hospitals in the city. The region is currently having four large district referral hospitals namely Mwananyamala Hospital, Temeke Hospital, Sinza-Palestina Hospital and Infectious Diseases Centre (IDC) each found in Kinondoni, Temeke, Ubungo and Ilala districts respectively. 45 people were interviewed on their consent, among them, there were relevant users of the proposed system, Information Technologists, System Administrators and HIV/AIDS healthcare practitioners in CTCs. These people were interviewed on the specific and general needs and requirements for the system. During the interview and discussion with them, the important system requirements were noted down for requirement specification. The collected information was then analyzed using the qualitative data analysis software, NVivo 11.

The captured requirements were analyzed using graphical languages based on the Unified Modelling Language (UML) rules and artefacts [38-40]. This was done using a computer software, starUML. StarUML was used for mapping the collected requirements into the use case diagrams of subsystems. The establishment of the use case diagrams were useful in developing the conceptual framework of the system.

\section{FINDINGS}

\section{A. Key players or actors.}

The study established the key players or actors who are 
involved in the process of dissemination of all kinds of HIV/AIDS healthcare information. The study came up with three different groups of actors such as clients who are ordinary people in need of accessing the HIV/AIDS healthcare clinical information for their health benefits; second group is the HIV/AIDS healthcare practitioners who are responsible for provision of all HIV/AIDS clinical information, consultations, recommendation and HIV/AIDS health tips; and the last group is made up of researchers, policy makers and other associated HIV/AIDS healthcare stakeholders who are in need of the accurate HIV/AIDS related data for further researching, further planning, and policy making and implementation.

\section{B. HIV/AIDS Healthcare Information Types}

There are different types of healthcare information such as appointment and medication reminders, general health tips, diagnostic information, symptoms and vital signs [41]. This study captured the key types of healthcare information which are provided or delivered by the HIV/AIDS CTCs. These healthcare information types include the provision of HIV/AIDS health tips, HIV/AIDS healthcare recommendations, HIV/AIDS clinical face-to-face counselling or consultation between the client and HIV/AIDS healthcare practitioner, and HIV/AIDS statistical reports. These services are to remain as the key services even when the HIV/AIDS healthcare information delivery is through the mobile application and web-based system. The key items for each of information type are as shown in the tables 1 to 4 .

HIV/AIDS Health Tip: An HIV/AIDS health tip is a set of HIV/AIDS healthcare related information. These tips should be given by the qualified HIV/AIDS healthcare practitioners to the clients. Table 1 below shows the key items forming HIV/AIDS health tip and their respective data types.

Table 1. Key Items of an HIV/AIDS Healthcare Tip

\begin{tabular}{cc}
\hline Key Item & Data Type \\
\hline Title/Subject & Text \\
Detail & Text \\
Category & Text \\
Date Posted & Date/Time (Timestamp) \\
Author ID or Name & Integer/Text \\
\hline
\end{tabular}

HIV/AIDS Healthcare Recommendation: An HIV/AIDS recommendation is a set of HIV/AIDS related information that is advised or proposed by an HIV/AIDS practitioner to a specific person/service client based on his/her previously described information. The key items forming an HIV/AIDS healthcare recommendation are shown in the table 2 below.
Table 2. Key Items of an HIV/AIDS Healthcare Recommendation

\begin{tabular}{cc}
\hline Key Item & Data Type \\
\hline Title/Subject & Text \\
Detail & Text \\
Category & Text \\
Requester/Client ID & Integer \\
Date Requested & Date/Time (Timestamp) \\
Recommender (Practitioner) & Integer/Text \\
ID/Name & Date/Time (Timestamp) \\
\hline Date Recommended &
\end{tabular}

HIV/AIDS Clinical Counselling: An HIV/AIDS clinical counselling or consultation involves the to-andfro exchange of information between the client and HIV/AIDS healthcare practitioner. This has been done by directly face-to-face conversation between the client and healthcare practitioner in the consultation room. In developing the mobile application and web-based system, this should be implemented via the real-time message exchange.

Table 3. Key Items of an HIV/AIDS Clinical Counselling/Consultation Chatroom

\begin{tabular}{cc}
\hline Key Item & Data Type \\
\hline Client ID & Integer \\
Practitioner ID/Name & Integer/Text \\
Message & Text \\
Date and Time & Date/Time (Timestamp) \\
\hline
\end{tabular}

HIV/AIDS Statistical Reports: These are reports of different statistical data based on the HIV/AIDS healthcare services. These reports are for providing information to help researchers, investigators and even the policy makers in making some critical decisions regarding the HIV/AIDS [42].

Table 4. Key Items of an HIV/AIDS Statistical Report

\begin{tabular}{cc}
\hline Key Item & Data Type \\
\hline Title/Subject & Text \\
Detail & Text \\
Category & Text \\
Generation Date & Date/Time (Timestamp) \\
\hline
\end{tabular}

\section{Requirements Specification}

In this study, the gathered system requirements were grouped into functional and non-functional requirements. These are providing the guidelines for the implementation of the information system [13]. The tables 5 and 6 show the functional and non-functional requirements respectively. 


\section{Conceptual Use Case}

Table 5 above, of functional requirements has shown how the different actors (system administrator, HIV/AIDS practitioner and client) interact. The interaction can further be analyzed using the use case diagram. Use case diagram designates the anticipated functionality of the system on the system user's point of view; and interactions between users (external actors) and the system under consideration [39, 44]. At a high level of abstraction, Fig.1 and 2 show the complete functionality of the mobile application system for the HIV/AIDS healthcare information delivery. Fig. 1 and 2 show the use case diagram for the system administration and mobile healthcare clinic subsystems respectively.

Table 5. Functional Requirements

\begin{tabular}{|c|c|c|}
\hline Requirement & Description & Actor \\
\hline \multirow{3}{*}{$\begin{array}{l}\text { Users Registration and } \\
\text { Users' Accounts } \\
\text { Management }\end{array}$} & $\begin{array}{l}\text { All system clients must register themselves into the system, each of them } \\
\text { must create his/her own user profile; with the system providing each of them } \\
\text { with both username and password }\end{array}$ & Client \\
\hline & $\begin{array}{l}\text { All the HIV/AIDS healthcare practitioners must be registered in the system } \\
\text { based on the qualifications and roles; the system should provide each of them } \\
\text { with username and password }\end{array}$ & System Administrator \\
\hline & $\begin{array}{l}\text { The system should provide the system administrator with ability of deleting } \\
\text { or suspending HIV/AIDS practitioner's account }\end{array}$ & System Administrator \\
\hline \multirow{2}{*}{$\begin{array}{l}\text { Document Gallery } \\
\text { Management }\end{array}$} & $\begin{array}{l}\text { System administrator should manage the uploading, editing, and/or removing } \\
\text { of documents such as announcements, guidelines and other documents in } \\
\text { documents gallery }\end{array}$ & System Administrator \\
\hline & $\begin{array}{l}\text { The system should allow all registered and authorized users to view the } \\
\text { posted system management related and/or HIV/AIDS related posted } \\
\text { documents in the document gallery }\end{array}$ & All System's Users \\
\hline Reports Generation & $\begin{array}{l}\text { The system should be able to generate different reports for other stakeholders } \\
\text { such as researchers and policymakers }\end{array}$ & System Administrator \\
\hline \multirow{2}{*}{$\begin{array}{l}\text { Online HIV/AIDS Clinical } \\
\text { Consultation }\end{array}$} & $\begin{array}{l}\text { The system should allow the clients to get into an online consultation } \\
\text { chatroom }{ }^{1} \text { and request for clinical attention from HIV/AIDS healthcare } \\
\text { practitioners }\end{array}$ & Clients \\
\hline & $\begin{array}{l}\text { The system should allow the HIV/AIDS healthcare practitioners to interact } \\
\text { and/or respond to consultation requests }\end{array}$ & HIV/AIDS Practitioners \\
\hline \multirow{2}{*}{ HIV/AIDS Healthcare Tips } & $\begin{array}{l}\text { The system should allow the HIV/AIDS healthcare practitioners to upload, } \\
\text { add, edit and/or remove the HIV/AIDS related healthcare tips }\end{array}$ & HIV/AIDS Practitioners \\
\hline & $\begin{array}{l}\text { The system should all the registered clients to receive and view the } \\
\text { HIV/AIDS Healthcare tips }\end{array}$ & Clients \\
\hline \multirow{2}{*}{$\begin{array}{l}\text { HIV/AIDS Healthcare } \\
\text { Recommendations and } \\
\quad \text { Reminders }\end{array}$} & $\begin{array}{l}\text { The system should allow the HIV/AIDS healthcare practitioner to set, edit } \\
\text { and/or remove recommendation and/or reminders for a particular client } \\
\text { based on his/her health status }\end{array}$ & HIV/AIDS Practitioners \\
\hline & $\begin{array}{l}\text { The system should all the registered and authorized clients to receive and } \\
\text { view the HIV/AIDS healthcare recommendations, the recommendation } \\
\text { history and/or timely reminders }\end{array}$ & Clients \\
\hline \multirow{2}{*}{$\begin{array}{l}\text { Systems' Technical and } \\
\text { User Support }\end{array}$} & $\begin{array}{l}\text { The system should allow all users to request and receive the system usage } \\
\text { support in case of any difficulties }\end{array}$ & All user \\
\hline & The system should all the system administrators to support others users & System Administrator \\
\hline
\end{tabular}

\footnotetext{
${ }^{1}$ A consultation chatroom for real-time end-to-end conversation between a client and an HIV/AIDS healthcare practitioner through text messages.
} 
HIV/AIDS Healthcare Information Delivery in Tanzania using Integrated Mobile Application and

Table 6. Non-functional Requirements

\begin{tabular}{l}
\hline Requirement \\
\hline - The system should authenticate all users before allowing them to interact with the system functionalities. \\
- The system should maintain password best practices such as maintaining maximum and minimum \\
password age, password history, containing character mixing complexity of a predefined minimum length \\
and employing encryption for password storage [43].
\end{tabular}

Maintainability

The system should be easy maintained, i.e. the system should be able to add new functionality/features without any major redesign.

Short response time is required by the system.
The system should be easy scalable, i.e. increased depending on the demand.
The system should have ability to continue function accurately if the something wrong happens or multiple
Robustness
requests are received at the same time.

Operating System

Mobile application based on Android platform. The web-based system should be cross-platform of all browsers.

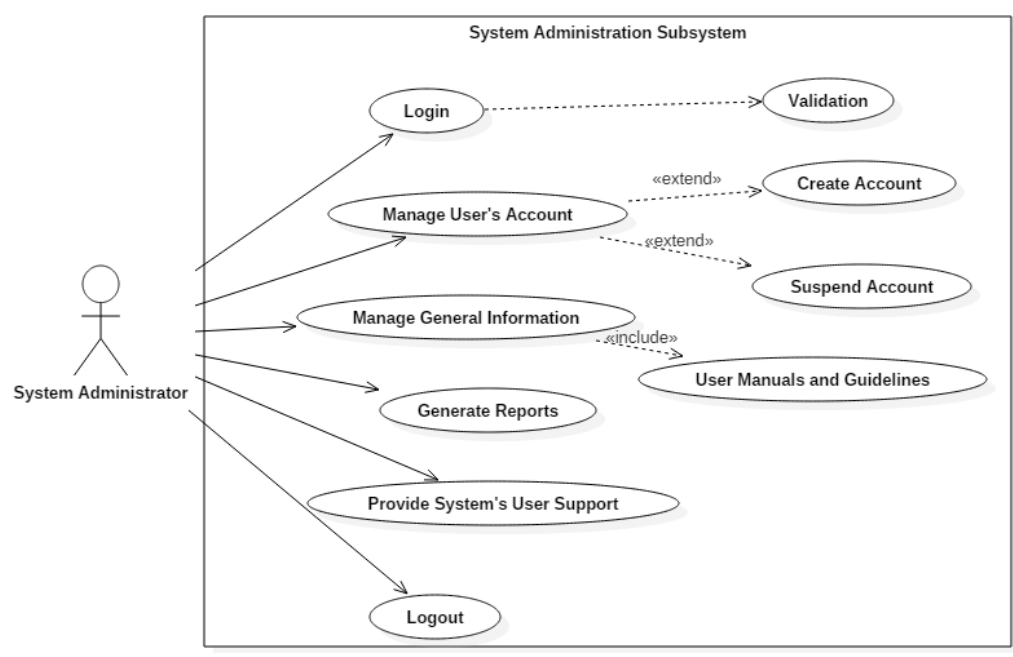

Fig.1. Use case diagram for the system administration subsystem

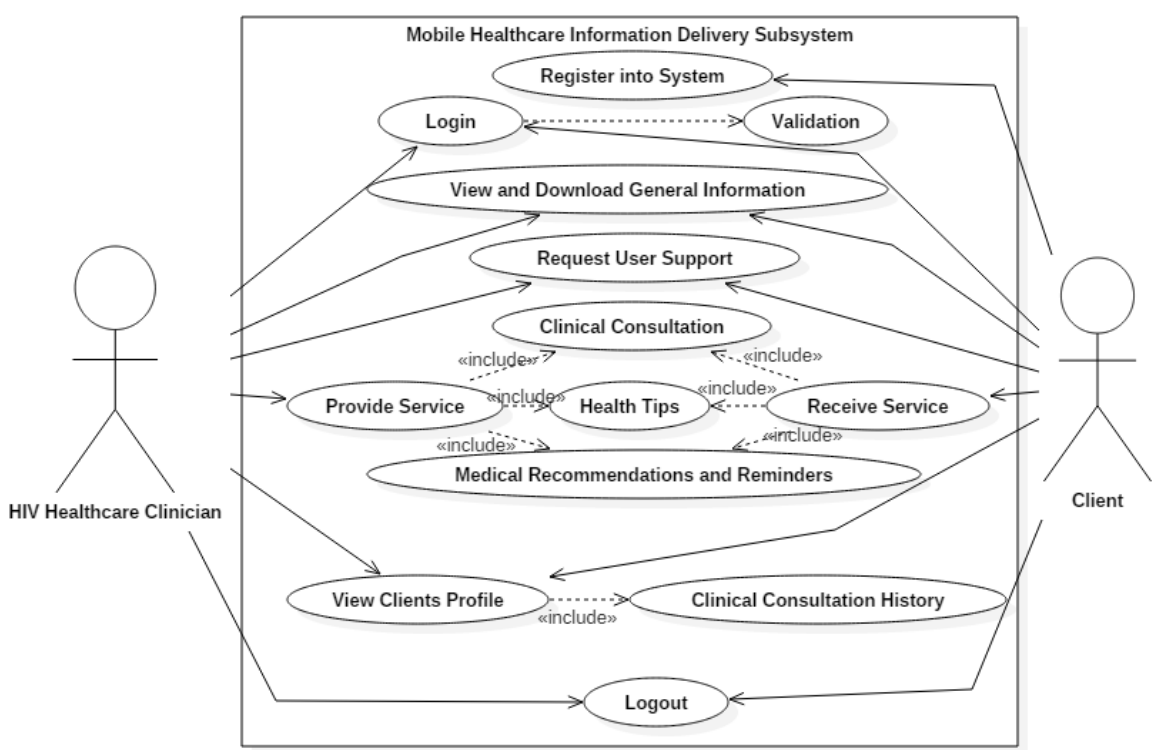

Fig.2. Use case diagram for mobile HIV/AIDS healthcare information delivery subsystem 


\section{E. Conceptual System Framework}

From the gathered and analyzed requirements above, the conceptual system diagram has been developed as seen in Fig. 3 below. The complete system will contain the application and database servers, client's user-end mobile application and/or the practitioner's web-based system and the internet connectivity infrastructure.

In Fig. 3 below shows that when the system platform is fully developed and hosted for online access then all the actors can use the system depending on their roles. The client is able to access the HIV/AIDS healthcare information through the developed mobile application via his/her mobile gadgets with internet capability. On the other hand, the HIV/AIDS practitioners in the HIV/AIDS CTCs are providing the HIV/AIDS healthcare clinical information service through the online system using the computers in their workstations. Furthermore, the other HIV/AIDS healthcare stakeholders such as the Government, researchers, HIV/AIDS related NonGovernment Organizations (NGO) who need the timely and relevant HIV/AIDS statistical data for fund raising, further researches, and policy making and implementation. These HIV/AIDS stakeholders can access these data through different reports which are generated by the system under the control of the system administrators.

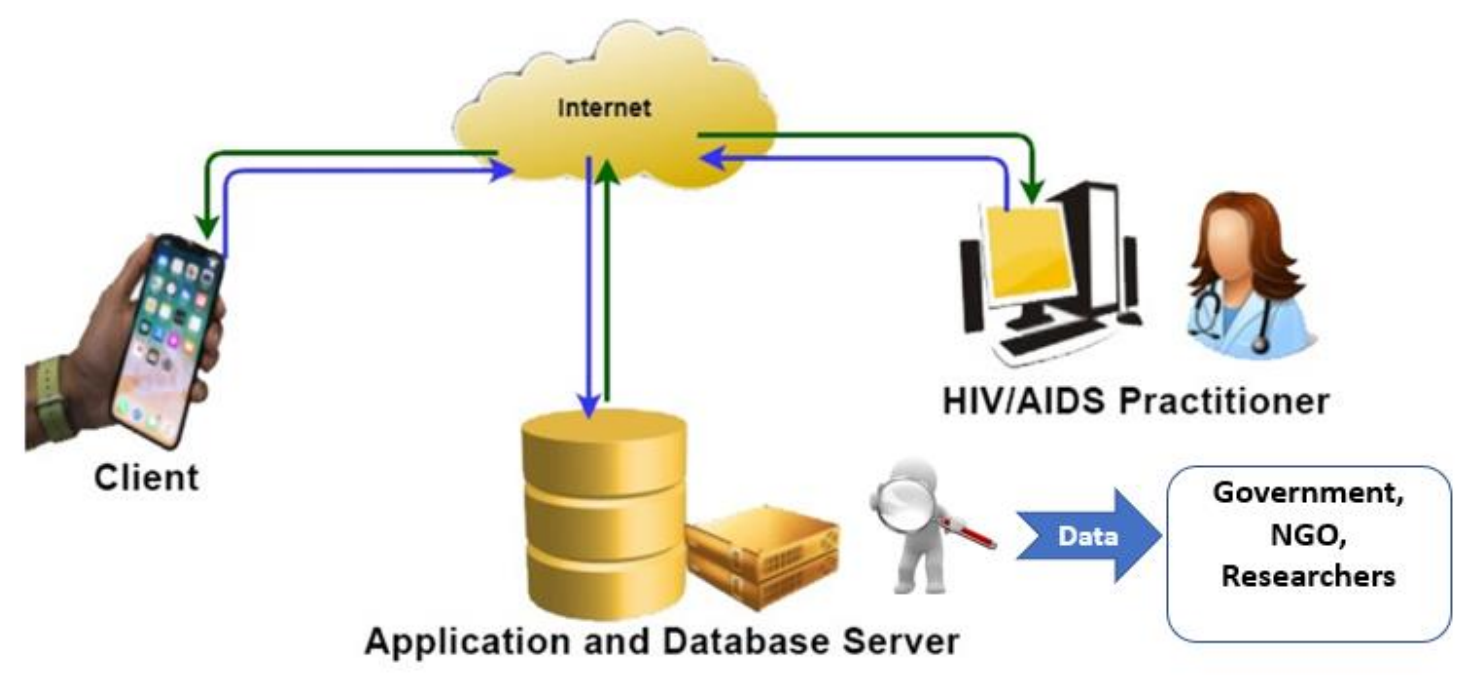

Fig.3. The Conceptual System Framework

\section{CONCLUSION}

This study was to identify the functional and nonfunctional requirements for the development of the mobile application and the web-based-system for the HIV/AIDS healthcare information delivery. These requirements were collected from the identified HIV/AIDS stakeholders. From the stakeholders, the functional and non-functional requirements were collected using the unstructured interviews, the collected qualitative information was analyzed using NVivo and modelled into use cases and conceptual framework using the starUML. These findings are essential to help the system developers in developing the secure m-health system for delivery of HIV/AIDS healthcare information.

HIV/AIDS healthcare providers, the ministry of health and all other stakeholders in fighting against HIV/AIDS can work on these findings as they provide the foundation for the development of a mobile application and webbased system for HIV/AIDS healthcare information delivery services. These online platforms planned to be developed can be made aware to the public in order to easy their hustle of seeking HIV/AIDS healthcare information.

\section{ACKNOWLEDGMENT}

The authors wish to thank Dr. Richard Z. Adam and Dr. Sam Makala for facilitating the data collection in the HIV/AIDS CTCs. This study was partially financed by the German Academic Exchange Service (DAAD).

\section{REFERENCES}

[1] K. Taghandiki, A. Zaeri, A. Shirani, "A Supervised Approach for Automatic Web Documents Topic Extraction Using Well-Known Web Design Features," International Journal of Modern Education and Computer Science (IJMECS), Vol.8, No.11, pp.20-27, 2016. DOI: 10.5815/ijmecs.2016.11.03

[2] J. Muthee, N. Mhando, "AMDI-BBC Summary Report," African Media Dev. Initiat. 2006.

[3] Global Stats, "Desktop vs Mobile vs Tablet Market Share in Africa - April 2018." Available: http://gs.statcounter.com/platform-market-share/desktopmobile-tablet/africa [Accessed: 16-May-2018].

[4] R. Meier, "Professional Android 2 Application Development" 2010

[5] P. Mechael, et al.,"Barriers and Gaps Affecting mHealth in Low and Middle Income Countries," Policy White Paper, 2010. 
[6] C. Z. Qiang, M. Yamamichi, V. Hausman, R. Miller, D. Altman, "Mobile Applications for the Health Sector," 2012.

[7] H. Cole-Lewis, T. Kershaw, "NIH Public Access," Epidemiol Rev, 2011, 32(1), 56-69. DOI: 10.1093/epirev/mxq004.

[8] Vital Wave Consulting. (2009). mHealth for Development: The Opportunity of Mobile Technology for Healthcare in the Developing World. Washington, D.C. and Berkshire, UK: UN Foundation-Vodafone Foundation Partnership.

[9] R. van Genuchten, W. Haring, D. van Kassel, K. Yakubi, "Mobile-phone Use in Tanzania," TAN2012 Mark. Res. 2012.

[10] E. T. Lwoga, T. Nagu, A. S. Sife, "Online HIV Information Seeking Behavior Among People Living with HIV in Selected Tanzanian Public Hospitals," Journal of Systems and Information Technology, Vol. 19 Issue: 1/2, pp.94-115, 2017. DOI: 10.1108/JSIT-06-2016-0038

[11] P. Loucopoulos, V. Karakostas, "System Requirements Engineering," 1995. McGraw-Hill, Inc. New York, NY, USA. ISBN:0077078438

[12] F. Cafer, S. Misra, "A cognitive requirement specification model in Computer and Information Sciences," 2009. ISCIS, 24th International Symposium on (pp. 518-521). IEEE.

[13] C. Ebert, "Dealing with nonfunctional requirements in large software systems", Annals of Software Engineering 3, 367-368. DOI:10.1023/A:1018933820619

[14] M. Glinz, "On Non-Functional Requirements," 15th IEEE International Requirements Engineering Conference (RE 2007), Delhi, 2007, pp. 21-26. DOI: 10.1109/RE.2007.45

[15] J. Mylopoulos, L. Chung, \& B. Nixon, "Representing and using nonfunctional requirements: a process-oriented approach," IEEE Transactions on Software Engineering, vol. 18, no. 6, pp. 483-497, Jun 1992. DOI: $10.1109 / 32.142871$

[16] The Joint United Nations Programme on HIV/AIDS, "Global HIV Statistics," 2016. Retrieved from www.unaids.org/sites/default/files/media_asset/globalAIDS-update-2016_en.pdf [Accessed on October 25, 2017].

[17] UNAIDS, "On the Fast-Track to end AIDS by 2030: Focus on location and population," 2015. Retrieved from http://www.unaids.org/sites/default/files/media_asset/WA D2015_report_en_part01.pdf

[18] L. V Mutasingwa, S. K. Mbirigenda, "Investigating Risky Sexual Behaviors among Youth in the Context of the HIV Epidemic in Mbeya Region, Tanzania," (March 2017). 2017.

[19] G. T. Feyissa, L. Abebe, E. Girma, M. Woldie, "Stigma and Discrimination Against People Living with HIV By Healthcare Providers, Southwest Ethiopia," BMC Public Health, 2012, 12, 522. DOI: 10.1186/1471-2458-12-522

[20] N. C. Mbonu, B. van den Borne, N. K. De Vries, "Stigma of People with HIV/AIDS in Sub-Saharan Africa: A Literature Review," Journal of Tropical Medicine, 2009, 1-14. DOI: $10.1155 / 2009 / 145891$

[21] M. Saki, S. M. K. Kermanshahi, E. Mohammadi, M. Mohraz, "Perception of Patients With HIV/AIDS from Stigma and Discrimination," Iranian Red Crescent Medical Journal, 17(6), 2015, e23638. DOI: 10.5812/ircmj.23638v2

[22] L. Cysneiros, J. do Prado Leite, J. de Melo Sabat Neto, "Requirements Engineering," 2001. 6: 97. DOI: 10.1007/s007660170008

[23] SDS Program, "Technical Assistance Surge 3 Participants Handbook: cascading innovations to generate and meet demand for quality social services," 2013.

[24] TAYOA, "National AIDS Helpline. Confidential information and behavior counseling," 2017. Retrieved from http://www.tayoa.org/tayoa/?page_id=349. Accessed on September 20, 2017.

[25] N. Mduma, K. Kalegele, "Enhancing Management of Nutrition Information Using Mobile Application: Prenatal and Postnatal Requirements," IST-Africa 2017 Conference Proceedings, International Information Management Corporation (IICM), 2017.

[26] N. Mduma, K. Kalegele, "An Integrated Mobile Application for Enhancing Management of Nutrition Information in Arusha Tanzania," International Journal of Computer Science and Information Security (IJCSIS), Vol. 13, No. 7, pp 34-38. 2015.

[27] MAMA (Mobile Alliance for Maternal Action), "Global Monitoring and Evaluation Framework," 2012. [Online]. Available http://www.mobilemamaalliance.org/sites/default/files/M AMA_Global_MEPlan_FINAL_all.pdf. [Accessed: 5May-2018].

[28] GSMA, "Mobile for Development, mHealth Country Feasibility Report: Tanzania," 2014. Available at: http://tanzania.gsmamhealthfeasibility.com/GSMA_mHea 1th_Country_Feasibility_Report_Tanzania_2015.pdf. [Accessed: 26-May-2018].

[29] I. A. Mwammenywa, S. F. Kaijage, "Towards Enhancing Access of HIV/AIDS Healthcare Information in Tanzania: Is a Mobile Application Platform a Way Forward?", International Journal of Information Technology and Computer Science (IJITCS), Vol.10, No.7, pp.31-38, 2018 DOI: $10.5815 / \mathrm{ijitcs} .2018 .07 .04$

[30] Ministry of Communications and Transport (The United Republic of Tanzania), "National Information and Communications Technologies Policy, (March 2003)." Retrieved from http://unpan1.un.org/intradoc/groups/public/documents/un pan/unpan033693.pdf [Accessed: 26-May-2018].

[31] P. Esselaar, O. Hesselmark, T. James, J. Miller, "Country ICT Survey for Tanzania: Final Report.” 2001.

[32] NACOPHA, "The People Living with HIV Stigma Index Report, (December 2015)." Retrieved from http://www.stigmaindex.org/sites/default/files/reports/Tan zaniaSTIGMA INDEX REPORT - Final Report pdf.pdf

[33] G. J. Monko, K. Kalegele, D. Machuve, "Web Services for Transforming e-Cultural Heritage Management in Tanzania", International Journal of Information Technology and Computer Science (IJITCS), Vol.9, No.12 pp.52-63, 2017. DOI: 10.5815/ijitcs.2017.12.07

[34] G. Somi., et al., "Three years of HIV/AIDS care and treatment services in Tanzania: achievements and challenges," Tanzania Journal of Health Research, 2009, 11(3).

[35] A. Kiwanuka, H. C. Kimaro, W. Senyoni, "Analysis of the acceptance process of district health information systems (DHIS) for vertical health programmes: a case study of TB, HIV/AIDS and malaria programmes in Tanzania," The Electronic Journal of Information Systems in Developing Countries, 2015, 70(1), pp.1-14.

[36] P. A. Manda, "Socio-cultural determinants of HIV/AIDS information impact: experiences from Babati district in Tanzania," IFLA publications, 2007, 124, p.167.

[37] C. N. Silva, "Designing qualitative research," Qualitative Social Research, 2008, Vol. 9, No. 3, pp. 1-6

[38] G. Booch, J. Rumbaugh I. Jacobson, "Unified Modeling Language User Guide," 2005, The, 2nd Edition. Addison Wesley Professional 
[39] A. Cockburn, "Writing effective use cases, The crystal collection for software professionals," 2000, AddisonWesley Professional Reading.

[40] C. Larman, "Applying UML and Patterns: An Introduction to Object-Oriented Analysis and Design and Iterative Development," 2004, Third Edition Addison Wesley Professional

[41] K. J. Serrano, et al., "Willingness to Exchange Health Information via Mobile Devices: Findings from a Population-Based Survey," Ann Fam Med, 2016, 14(1), 34-40. DOI: 10.1370/afm.1888

[42] J. C. Bailar, F. Mosteller, "Guidelines for Statistical Reporting in Articles for Medical Journals: Amplifications and Explanations," Ann Intern Med, 1988, 108:266-273. DOI: 10.7326/0003-4819-108-2-266

[43] D. Ginsberg, "Password Best Practices. Presentations," 2014, 5. http://scholarship.kentlaw.iit.edu/lib_pres/5 [Accessed on October 25, 2017].

[44] Sparx Systems, "UML Tutorials", 2004. [Online]. Available http://www.sparxsystems.com/downloads/whitepapers/Th e_Use_Case_Model.pdf. [Accessed: 12-May-2018].

\section{Authors' Profiles}

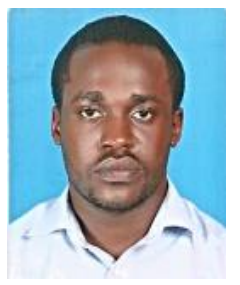

Ibrahim A. Mwammenywa is an ICT specialist and researcher in the ICT fields particularly in electronic health (e-health) and mobile applications. Currently, he is pursuing Master's Degree in Information and Communications Science and Engineering (ICSE) at the Nelson Mandela - African Institution of Science and Technology (NM-AIST).

He received his Bachelor's Degree in Telecommunications Engineering in 2014 at the University of Dar es Salaam (UDSM) and in the same year being registered by the Engineering Registration Boards (ERB) of Tanzania as a graduate engineer. $\mathrm{He}$ then worked with the state-owned telecommunications company, Tanzania Telecommunication Company Limited (TTCL); before joined the UDSM to work as the academician in December 2015.

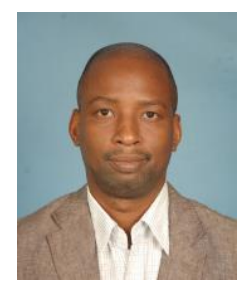

Shubi F. Kaijage obtained his Doctor of Engineering degree (Electronics and Information Eng.) from University of the Ryukyus, Okinawa, Japan, in March 2011. Since February 2014, he has been working with Nelson Mandela African Institution of Science and Technology (NM-AIST), Tanzania, in the school of Computational and Communication Science and Engineering (CoCSE).

$\mathrm{He}$ has vast experience of over 8 years of research in the areas of fiber optics, photonics and Terahertz technology, wireless sensor network \& RFID technologies. He worked as a Post-Doctoral Research Fellow at the Research Center of Terahertz Technology, Shenzhen University, P. R. China. He has published over 30 scientific papers in International peerreviewed journals and over 50 research works presented in various International conferences and workshops. Furthermore, he is a recipient of numerous International awards and grants as recognition to his scholarly works.

Shubi is the member of International professional societies including the Institute of Electrical and Electronics Engineering
(IEEE), African Academy of Sciences (AAS), and the Optical Society of America (OSA).

How to cite this paper: Ibrahim A. Mwammenywa, Shubi F. Kaijage, "HIV/AIDS Healthcare Information Delivery in Tanzania using Integrated Mobile Application and Web-based System: System's Functional and Non-functional Requirements", International Journal of Information Technology and Computer Science(IJITCS), Vol.10, No.11, pp.30-38, 2018. DOI: 10.5815/ijitcs.2018.11.03 